\title{
SUPERSTITIOUS BEHAVIOR AMONG JUDO, TAEKWONDO AND BOXING PLAYERS
}

\author{
Gaurav Dureja, Gagandeep Singh
}

Department of Physical Education-TEL \& R, Postgraduate Government College, Sector-11, Chandigarh (U.T.), India

\begin{abstract}
Purpose: The present study was designed to measure superstitious behavior among Judo, Taekwondo and Boxing players. Material: Thirty $(\mathrm{N}=30)$ male inter-college level players with the age group of 19-25 years were selected through purposive sampling technique to act as subjects from affiliated colleges of Panjab University, Chandigarh. They were further divided into three groups: Group-A [Judo ( $\mathrm{n}=10$ )], Group-B [Taekwondo $(n=10)]$ and Group-C [Boxing $(n=10)]$. One Way Analysis of Variance (ANOVA) was applied to find out the differences among judo, taekwondo and boxing players. Where ' $F$ ' values found significant, Least Significant Differences (LSD) Post-hoc test was applied to find out the direction and degree of difference. Results: The level of significance was set at 0.05 . The result revealed significant differences among judo, taekwondo and boxing players on the sub parameters: clothing and appearance, preparation, team ritual and coach. However, no significant differences have been observed on the sub-parameters fetish, game/competition, prayer and parameter superstitious (Total). Conclusions: The obtained results showed significant differences on the sub-parameter Coach among Judo, Taekwondo and Boxing players. While calculating the mean values of entire groups, it has been observed that Boxing players demonstrate significantly better on the sub-parameter Coach. Therefore, it can be ascertained that Boxing players are more confident that coach bring a lucky charm to our game.
\end{abstract}

Keywords: Superstitious behavior, Judo, Taekwondo, Boxing, players.

\section{Introduction}

Superstitions are regarded as "a belief that one's fate is in the hands of unknown external powers governed by forces over which one has no control" [8]. Superstitions are irrational beliefs that influence the emotional states of people who hold them. They are learned forms of behavior, or dispositions about objects or situations, that direct the holder toward some preferred response [7]. Wann et al. [12] describe superstitious behavior as an action or series of actions believed to lead to or cause a specified, generally desirable, outcome. Brooks [3] explains that people engage in superstitious behaviors when they feel as if they are losing control over their own lives and their brains are searching for order and structure. Cultural and environmental factors also play a role. For example, it has been found that persons in high risk areas in the Middle East, currently in a state of disarray, are more likely to carry a lucky charm in hopes of regaining some order and structure and reducing some of their internal chaos [3].

Superstition in sports can be defined as "actions which are repetitive, formal, sequential, and distinct from technical performance and which the athlete believes to be powerful in controlling luck or other external factors" [2]. The repetitive nature of such events allows for the term 'ritual' to be used to describe these superstitious behaviors. A ritual in sport is usually defined as conscious activity involving heightened arousal with focused attention that provides a way of coping with a high stress situation [15].

Superstitious practices in sports have been linked to the theoretical perspectives of attribution [6], achievement motivation [13], reinforcement [9], and locus of control [16]. Attribution theory is based on individual perceptions about success and failure and relates to the need for achievement. Weiner [13] believed that when achievement is aroused, we tend to attribute our performance to a variety of possible causes or attribution elements, such as ability, effort, or luck. Athletes, competing under extreme conditions, may often feel that they don't have enough control over uncertainty, which affects their performance. Engaging in superstitious behavior can offer the assurance of illusory control in a high-stress or uncertain situation. If subsequent accidental connections are made between the ritual and favorable consequences, the behavior will be maintained as a superstition despite instances that go without such reinforcement. It is the chance element that is often present in sport, which contributes to the athlete's feelings of uncertainty and lack of control [11]. Therefore, the present study was designed with the purpose to investigate the superstitious behaviour among Judo, Taekwondo and Boxing players.

\section{Method and material}

Sample: Thirty $(\mathrm{N}=30)$ male inter-college level players with the age group of 19 to 25 years were selected through purposive sampling technique to act as subjects from, affiliated colleges of Panjab University, Chandigarh. They were further divided into three groups: Group-A [Judo $(n=10)$ ], Group-B [Taekwondo $(n=10)$ ] and Group-C [Boxing $(\mathrm{n}=10)]$.

\section{Instrument:}

The superstitious Questionnaire developed by Bleak and Frederick (1998) was administrated. 


\section{Statistical Techniques:}

One Way Analysis of Variance (ANOVA) was employed to find out the differences among Judo, Taekwondo and Boxing players. Where ' $F$ ' values found significant, Least Significant Differences (LSD) Posthoc test was applied to find out the direction and degree of difference. The level of significance was set at 0.05 .

Results

Table 1. Descriptive analysis among Judo, Taekwondo and Boxing on the sub-parameter clothing and appearance

\begin{tabular}{llllll}
\hline S. No. & Groups & $\mathbf{N}$ & Mean & Std. Deviation & Std. Error \\
\hline 1. & Judo & 10 & 27.50 & 4.11 & 1.30 \\
2. & Taekwondo & 10 & 34.10 & 7.69 & 2.43 \\
3. & Boxing & 10 & 31.30 & 2.83 & .89 \\
& Total & 30 & 30.96 & 5.80 & 1.05 \\
\hline
\end{tabular}

Table 1 depicts the results Judo, Taekwondo and Boxing players on the sub-parameter Clothing and Appearance. The scores of Judo players showed the Mean and SD values as 27.50 and 4.11 respectively. The scores of Taekwondo players showed the Mean and SD values as 34.10 and 7.69 respectively. However, the scores of Boxing players showed had Mean and SD values as 31.30 and 2.83 respectively.

Table 2. One way analysis of variance (Anova) results among judo, taekwondo and boxing players with regard to the sub-parameter clothing and appearance

\begin{tabular}{llllll}
\hline Source of Variation & Sum of Squares & $\begin{array}{l}\text { Degree } \\
\text { of Freedom }\end{array}$ & Mean Square & F-Value & $\begin{array}{l}\text { P-Value } \\
\text { (Sig.) }\end{array}$ \\
\hline Between Groups & 219.46 & 2 & 109.73 & & \\
Within Groups & 757.50 & 27 & 28.05 & 3.91 & $.03^{*}$ \\
Total & 976.96 & 29 & & & \\
\hline
\end{tabular}

* Confident at 0.05

It can be seen from table 2 that significant differences were found with regard to the sub-parameter Clothing and Appearance among Judo, Taekwondo and Boxing players as the P-value (Sig.) .03 was found smaller than 0.05 level of significance $(\mathrm{p}<0.05)$.

Since the obtained F-value was found significant, therefore, least significant difference (LSD) Post-hoc test was employed to study the direction and significance of difference between paired means among Judo, Taekwondo and Boxing players on the sub-parameter Clothing and Appearance. The results of LSD Post-hoc test have been presented in Table 3 .

Table 3. Analysis of least significant difference (LSD) post-hoc test among judo, taekwondo and boxing players on the sub-parameter clothing and appearance

\begin{tabular}{llll}
\hline Means & Mean Difference & P-Value (Sig.) \\
\hline $\begin{array}{l}\text { Judo } \\
(27.50)\end{array}$ & $\begin{array}{l}\text { Taekwondo } \\
(34.10) \\
\text { Boxing } \\
(31.30)\end{array}$ & 6.60 & $.01^{*}$ \\
Taekwondo & $\begin{array}{l}\text { Judo } \\
(27.50)\end{array}$ & 6.80 & .12 \\
$(34.10)$ & $\begin{array}{l}\text { Boxing } \\
(31.30)\end{array}$ & 2.80 & $.01^{*}$ \\
Joxing & $\begin{array}{l}\text { Judo } \\
(27.50)\end{array}$ & 3.80 & .24 \\
$(31.30)$ & $\begin{array}{l}\text { Taekwondo } \\
(34.10)\end{array}$ & 2.80 & .12 \\
\hline
\end{tabular}

\section{* Confident at 0.05}

It has been observed from the Table 3 that mean difference between judo and taekwondo players was found 6.60. The P-value (Sig.) .01 showed that taekwondo players had demonstrated significantly better clothing and appearance than their counterpart judo players. 
The mean difference between judo and boxing players was found 3.80. The P-value (Sig.) .12 revealed that boxing players had exhibited better clothing and appearance though not significantly than their counterpart judo players.

The mean difference between taekwondo and boxing players was found 2.80. The P-value (Sig.) .24 revealed that taekwondo players had exhibited better clothing and appearance though not significantly than their counterpart boxing players. The graphical representation of means scores of clothing and appearance among Judo, Taekwondo and Boxing players has been exhibited in Figure 1.

scores

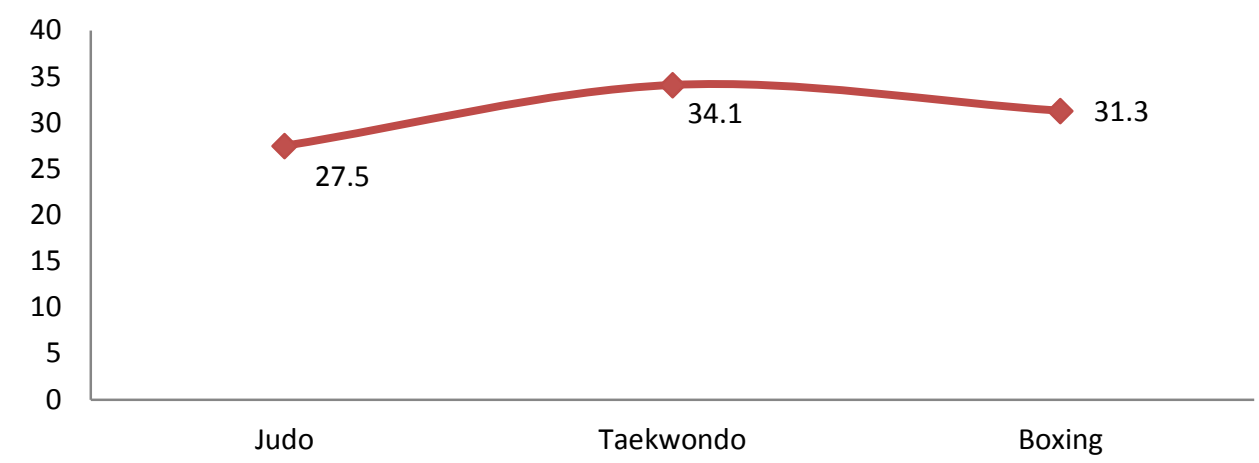

Figure 1. Graphical representation of mean scores with regard to judo, taekwondo and boxing players on the sub-parameter clothing and appearance

Table 4. Descriptive analysis among judo, taekwondo and boxing players on the sub-parameter fetish

\begin{tabular}{llllll}
\hline S. No. & Groups & N & Mean & Std. Deviation & Std. Error \\
\hline 1. & Judo & 10 & 14.90 & 7.20 & 2.27 \\
2. & Taekwondo & 10 & 13.30 & 4.92 & 1.55 \\
3. & Boxing & 10 & 17.00 & 4.24 & 1.34 \\
& Total & 30 & 15.06 & 5.61 & 1.02 \\
\hline
\end{tabular}

Table 4 depicts the results among Judo, Taekwondo and Boxing players on the sub-parameter Fetish. The scores of judo players showed the Mean and SD values as 14.90 and 7.20 respectively. The scores of taekwondo players showed the Mean and SD values as 13.30 and 4.92 respectively. However, the scores of boxing players showed had Mean and SD values as 17.00 and 4.24 respectively.

Table 5. One way analysis of variance (Anova) results among judo, taekwondo and boxing players with regard to the sub-parameter fetish

\begin{tabular}{llllll}
\hline Source of Variation & Sum of Squares & $\begin{array}{l}\text { Degree } \\
\text { of Freedom }\end{array}$ & Mean Square & F-Value & $\begin{array}{l}\text { P-Value } \\
\text { (Sig.) }\end{array}$ \\
\hline Between Groups & 68.86 & 2 & 34.43 & & .34 \\
Within Groups & 847.00 & 27 & 31.37 & 1.09 & \\
Total & 915.86 & 29 & & & \\
\hline
\end{tabular}

* Confident at 0.05

It can be seen from Table 5 that insignificant differences were found with regard to the sub-parameter Fetish among Judo, Taekwondo and Boxing players as the P-value (Sig.) .34 was found higher than the 0.05 level of significance $(\mathrm{p}>0.05)$. Since F-value was found insignificant, therefore, there is no need to apply Post-hoc test.

Table 6. Descriptive analysis among judo, taekwondo and boxing players on the sub-parameter preparation

\begin{tabular}{llllll}
\hline S. No. & Groups & $\mathbf{N}$ & Mean & Std. Deviation & Std. Error \\
\hline 1. & Judo & 10 & 14.90 & 2.42 & .76 \\
2. & Taekwondo & 10 & 21.50 & 4.62 & 1.46 \\
3. & Boxing & 10 & 17.20 & 3.39 & 1.07 \\
& Total & 30 & 17.86 & 4.44 & .81 \\
\hline
\end{tabular}

Table 6 depicts the results among Judo, Taekwondo and Boxing players on the sub-parameter Preparation. The scores of judo players showed the Mean and SD values as 14.90 and 2.42 respectively. The scores of 
taekwondo players showed the Mean and SD values as 21.50 and 4.62 respectively. However, the scores of boxing players showed had Mean and SD values as 17.20 and 3.39 respectively.

Table 7. One way analysis of variance (Anova) results among judo, taekwondo and boxing players with regard to the sub-parameter preparation

\begin{tabular}{llllll}
\hline Source of Variation & Sum of Squares & $\begin{array}{l}\text { Degree } \\
\text { of freedom }\end{array}$ & Mean Square & F-Value & $\begin{array}{l}\text { P-Value } \\
\text { (Sig.) }\end{array}$ \\
\hline Between Groups & 224.46 & 2 & 112.23 & & $.00^{*}$ \\
Within Groups & 349.00 & 27 & 12.92 & 8.68 & \\
Total & 573.46 & 29 & & & \\
\hline
\end{tabular}

* Confident at 0.05

It can be seen from Table 7 that significant differences were found with regard to the sub-parameter Preparation among Judo, Taekwondo and Boxing players as the P-value (Sig.) .00 was found smaller than 0.05 level of significance $(\mathrm{p}<0.05)$.

Since the obtained F-value was found significant, therefore, least significant difference (LSD) Post-hoc test was employed to study the direction and significance of difference between paired means among Judo, Taekwondo and Boxing players on the sub-parameter preparation. The results of LSD Post-hoc test have been presented in Table 8 .

Table 8. Analysis of least significant difference (LSD) post-hoc test among judo, taekwondo and boxing players on the sub-parameter preparation

\begin{tabular}{|c|c|c|c|}
\hline Means & & Mean Difference & P-Value (Sig.) \\
\hline \multirow[t]{2}{*}{$\begin{array}{l}\text { Judo } \\
(14.90)\end{array}$} & $\begin{array}{l}\text { Taekwondo } \\
(21.50)\end{array}$ & 6.60 & $.00^{*}$ \\
\hline & $\begin{array}{l}\text { Boxing } \\
(17.20)\end{array}$ & 2.30 & .16 \\
\hline \multirow[t]{2}{*}{$\begin{array}{l}\text { Taekwondo } \\
(21.50)\end{array}$} & $\begin{array}{l}\text { Judo } \\
(14.90)\end{array}$ & 6.60 & .00 \\
\hline & $\begin{array}{l}\text { Boxing } \\
(17.20)\end{array}$ & $4.30^{*}$ & $.01^{*}$ \\
\hline \multirow[t]{2}{*}{$\begin{array}{l}\text { Boxing } \\
(17.20)\end{array}$} & $\begin{array}{l}\text { Judo } \\
\text { (14.90) }\end{array}$ & 2.30 & .16 \\
\hline & $\begin{array}{l}\text { Taekwondo } \\
(21.50)\end{array}$ & $4.30^{*}$ & $.01^{*}$ \\
\hline
\end{tabular}

* Confident at 0.05

It has been observed from the Table 8 that mean difference between judo and taekwondo players was found 6.60. The P-value (Sig.) .00 showed that taekwondo players had demonstrated significantly better preparation than their counterpart judo players.

The mean difference between judo and boxing players was found 2.30. The P-value (Sig.) .16 revealed that boxing players had exhibited better preparation though not significantly than their counterpart judo players.

It has been observed from the Table 8 that mean difference between judo and taekwondo players was found 4.30 The P-value (Sig.) .01 showed that taekwondo players had demonstrated significantly better preparation than their counterpart judo players. The graphical representation of means scores of preparation among Judo, Taekwondo and Boxing players has been exhibited in Figure 2.

Table 9. Descriptive analysis among judo, taekwondo and boxing players on the sub-parameter game/competition

\begin{tabular}{llllll}
\hline S. No. & Groups & N & Mean & Std. Deviation & Std. Error \\
\hline 1. & Judo & 10 & 13.50 & 3.20 & 1.01 \\
2. & Taekwondo & 10 & 12.30 & 4.24 & 1.34 \\
3. & Boxing & 10 & 11.70 & 3.71 & 1.17 \\
& Total & 30 & 12.50 & 3.69 & .67 \\
\hline
\end{tabular}


Table 9 depicts the results among Judo, Taekwondo and Boxing players on the sub-parameter Game/Competition. The scores of Judo players showed the Mean and SD values as 13.50 and 3.20 respectively. The scores of Taekwondo players showed the Mean and SD values as 12.30 and 4.24 respectively. However, the scores of Boxing players showed had Mean and SD values as 11.70 and 3.71 respectively.

scores

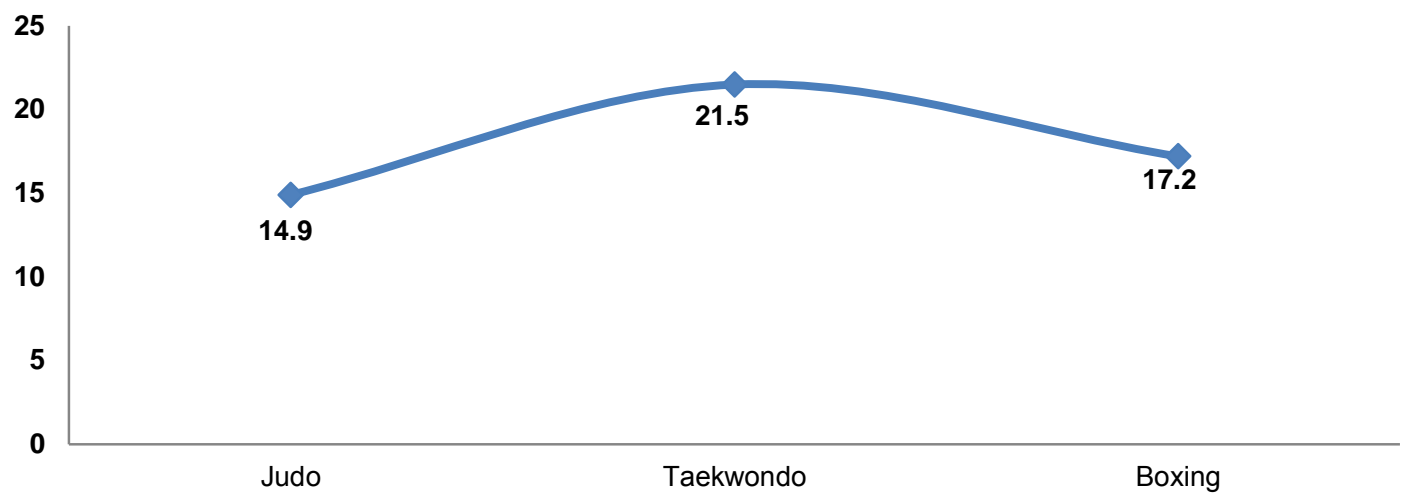

Figure 2. Graphical representation of mean scores with regard to judo, taekwondo and boxing players on the sub-parameter preparation

Table 10. One way analysis of variance (Anova) results among judo, taekwondo and boxing players with regard to the sub-parameter game/competition

\begin{tabular}{llllll}
\hline Source of Variation & Sum of Squares & $\begin{array}{l}\text { Degree } \\
\text { of Freedom }\end{array}$ & Mean Square & F-Value & $\begin{array}{l}\text { P-Value } \\
\text { (Sig.) }\end{array}$ \\
\hline Between Groups & 16.80 & 2 & 8.40 & \\
Within Groups & 378.70 & 27 & 14.02 & .59 & .55 \\
Total & 395.50 & 29 & & & \\
\hline
\end{tabular}

* Confident at 0.05

It can be seen from Table 10 that insignificant differences were found with regard to the sub-parameter Game/Competition among Judo, Taekwondo and Boxing players as the P-value (Sig.) .55 was found higher than the 0.05 level of significance ( $p>0.05$ ). Since F-value was found insignificant, therefore, there is no need to apply Post-hoc test.

Table 11. Descriptive analysis among judo, taekwondo and boxing players on the sub-parameter team ritual

\begin{tabular}{|c|c|c|c|c|c|}
\hline S. No. & Groups & $\mathbf{N}$ & Mean & Std. Deviation & Std. Error \\
\hline 1. & Judo & 10 & 14.60 & 3.86 & 1.22 \\
\hline 2. & Taekwondo & 10 & 11.80 & 2.57 & .81 \\
\hline \multirow[t]{2}{*}{3.} & Boxing & 10 & 9.90 & 3.60 & 1.13 \\
\hline & Total & 30 & 12.10 & 3.81 & .69 \\
\hline
\end{tabular}

Table 11 depicts the results among Judo, Taekwondo and Boxing players on the sub-parameter Team Ritual. The scores of judo players showed the Mean and SD values as 14.60 and 3.86 respectively. The scores of taekwondo players showed the Mean and SD values as 11.80 and 2.57 respectively. However, the scores of boxing players showed had Mean and SD values as 9.90 and 3.60 respectively.

Table 12. One way analysis of variance (Anova) results among judo, taekwondo and boxing players with regard to the sub-parameter team ritual

\begin{tabular}{llllll}
\hline Source of Variation & Sum of Squares & $\begin{array}{l}\text { Degree } \\
\text { of Freedom }\end{array}$ & Mean Square & F-Value & $\begin{array}{l}\text { P-Value } \\
\text { (Sig.) }\end{array}$ \\
\hline Between Groups & 111.80 & 2 & 55.90 & & $.01^{*}$ \\
Within Groups & 310.90 & 27 & 11.51 & 4.85 & \\
Total & 422.70 & 29 & & & \\
\hline
\end{tabular}

* Confident at 0.05 
It can be seen from Table 12 that significant differences were found with regard to the sub-parameter Team Ritual among Judo, Taekwondo and Boxing players as the P-value (Sig.) .01 was found smaller than 0.05 level of significance $(\mathrm{p}<0.05)$.

Since the obtained F-value was found significant, therefore, least significant difference (LSD) Post-hoc test was employed to study the direction and significance of difference between paired means among Judo, Taekwondo and Boxing players on the sub-parameter Team Ritual. The results of LSD Post-hoc test have been presented in Table 13.

Table 13. Analysis of least significant difference (LSD) post-hoc test among judo, taekwondo and boxing players on the sub-parameter team ritual

\begin{tabular}{llll}
\hline Means & Mean Difference & P-Value (Sig.) \\
\hline $\begin{array}{llll}\text { Judo } \\
(14.60)\end{array}$ & $\begin{array}{l}\text { Taekwondo } \\
(11.80) \\
\text { Boxing } \\
(9.90)\end{array}$ & 2.80 & .07 \\
Taekwondo & $\begin{array}{l}\text { Judo } \\
(14.60)\end{array}$ & 2.80 & $.00^{*}$ \\
$(11.80)$ & $\begin{array}{l}\text { Boxing } \\
(9.90)\end{array}$ & 1.90 & .07 \\
Judo & 4.70 & .22 \\
$(9.90)$ & $\begin{array}{l}(14.60) \\
\text { Taekwondo }\end{array}$ & 1.90 & $.00^{*}$ \\
$(11.80)$ & & .22 \\
\hline
\end{tabular}

* Confident at 0.05

It has been observed from the Table 13 that mean difference between judo and taekwondo players was found 2.80. The P-value (Sig.) .07 showed that judo players had demonstrated significantly better Team Ritual than their counterpart taekwondo players.

It has been observed from the Table 13 that mean difference between judo and boxing players was found 4.70. The P-value (Sig.) .00 showed that judo players had demonstrated significantly better Team Ritual than their counterpart boxing players.

The mean difference between taekwondo and boxing players was found 1.90. The P-value (Sig.) .22 revealed that taekwondo players had exhibited better Team Ritual though not significantly than their counterpart boxing players. The graphical representation of means scores of Team Ritual among Judo, Taekwondo and Boxing players has been exhibited in Figure 3.

scores

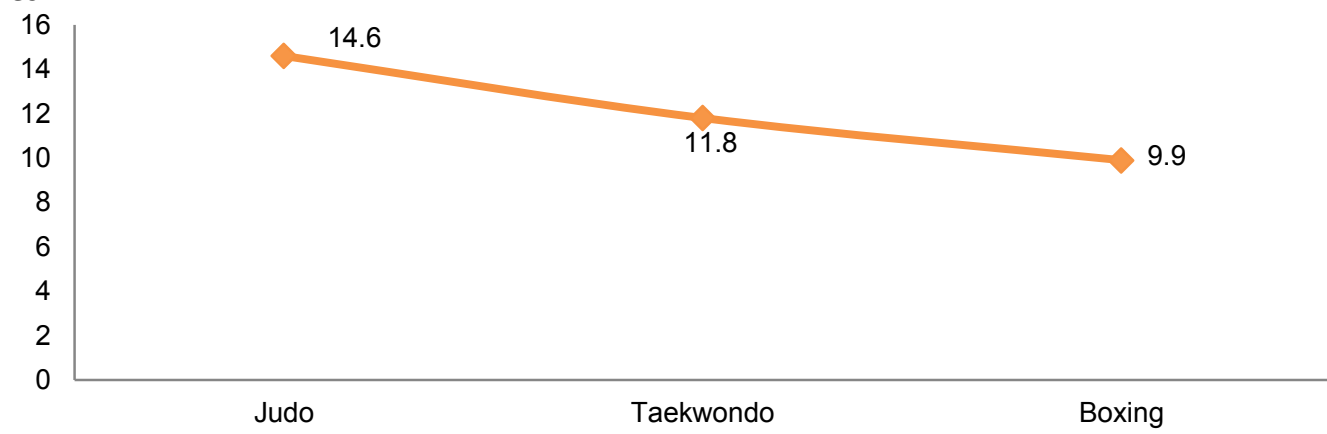

Figure 3. Graphical representation of mean scores with regard to judo, taekwondo and boxing players on the sub-parameter team ritual

Table 14. Descriptive analysis among judo, taekwondo and boxing players on the sub-parameter prayer

\begin{tabular}{llllll}
\hline S. No. & Groups & $\mathbf{N}$ & Mean & Std. Deviation & Std. Error \\
\hline 1. & Judo & 10 & 8.70 & 3.02 & .95 \\
2. & Taekwondo & 10 & 8.40 & 3.02 & .95 \\
3. & Boxing & 10 & 8.20 & 3.19 & 1.00 \\
& Total & 30 & 8.43 & 2.97 & .54 \\
\hline
\end{tabular}


Table 14 depicts the results among Judo, Taekwondo and Boxing players on the sub-parameter Prayer. The scores of judo players showed the Mean and SD values as 8.70 and 3.02 respectively. The scores of taekwondo players showed the Mean and SD values as 8.40 and 3.02 respectively. However, the scores of boxing players showed had Mean and SD values as 8.20 and 3.19 respectively.

Table 15. One way analysis of variance (Anova) results among judo, taekwondo and boxing players with regard to the sub-parameter prayer

\begin{tabular}{llllll}
\hline Source of Variation & Sum of Squares & $\begin{array}{l}\text { Degree } \\
\text { of Freedom }\end{array}$ & Mean Square & F-Value & $\begin{array}{l}\text { P-Value } \\
\text { (Sig.) }\end{array}$ \\
\hline Between Groups & 1.26 & 2 & .633 & & .93 \\
Within Groups & 256.10 & 27 & 9.48 & .06 & .93 \\
Total & 257.36 & 29 & & & \\
\hline
\end{tabular}

* Confident at 0.05

It can be seen from Table 15 that insignificant differences were found with regard to the sub-parameter Prayer among Judo, Taekwondo and Boxing players as the P-value (Sig.) .93 was found higher than the 0.05 level of significance $(\mathrm{p}>0.05)$. Since F-value was found insignificant, therefore, there is no need to apply Post-hoc test.

Table 16. Descriptive analysis among judo, taekwondo and boxing players on the sub-parameter coach

\begin{tabular}{llllll}
\hline S. No. & Groups & $\mathbf{N}$ & Mean & Std. Deviation & Std. Error \\
\hline 1. & Judo & 10 & 5.20 & 2.04 & .64 \\
2. & Taekwondo & 10 & 7.20 & 2.20 & .69 \\
3. & Boxing & 10 & 8.60 & 2.87 & .90 \\
& Total & 30 & 7.00 & 2.71 & .49 \\
\hline
\end{tabular}

Table 16 depicts the results among Judo, Taekwondo and Boxing players on the sub-parameter Coach. The scores of judo players showed the Mean and SD values as 5.20 and 2.04 respectively. The scores of taekwondo players showed the Mean and SD values as 7.20 and 2.20 respectively. However, the scores of boxing players showed had Mean and SD values as 8.60 and 2.87 respectively.

Table 17. One way analysis of variance (Anova) results among judo, taekwondo and boxing players with regard to the sub-parameter coach

\begin{tabular}{llllll}
\hline Source of Variation & Sum of Squares & $\begin{array}{l}\text { Degree } \\
\text { of Freedom }\end{array}$ & Mean Square & F-Value & $\begin{array}{l}\text { P-Value } \\
\text { (Sig.) }\end{array}$ \\
Between Groups & 58.40 & 2 & 29.20 & & \\
Within Groups & 155.60 & 27 & 5.76 & 5.06 & $.01^{*}$ \\
Total & 214.00 & 29 & & & \\
\hline
\end{tabular}

* Confident at 0.05

It can be seen from Table 17 that significant differences were found with regard to the sub-parameter Coach among Judo, Taekwondo and Boxing players as the P-value (Sig.) .01 was found smaller than 0.05 level of significance $(\mathrm{p}<0.05)$.

Since the obtained F-value was found significant, therefore, least significant difference (LSD) Post-hoc test was employed to study the direction and significance of difference between paired means among Judo, Taekwondo and Boxing players on the sub-parameter Coach. The results of LSD Post-hoc test have been presented in Table 18.

The mean difference between judo and taekwondo players was found 2.00. The P-value (Sig.) .07 revealed that taekwondo players had exhibited better Coach though not significantly than their counterpart judo players.

It has been observed from the Table 18 that mean difference between judo and boxing players was found 3.40. The P-value (Sig.) .00 showed that boxing players had demonstrated significantly better Coach than their counterpart judo players.

The mean difference between taekwondo and boxing players was found 1.40. The P-value (Sig.) .20 revealed that boxing players had exhibited better Coach though not significantly than their counterpart taekwondo players. The graphical representation of means scores of Coach among Judo, Taekwondo and Boxing players has been exhibited in Figure 4. 
Table 18. Analysis of least significant difference (LSD) post-hoc test among judo, taekwondo and boxing players on the sub-parameter coach

\begin{tabular}{|c|c|c|c|}
\hline \multicolumn{2}{|l|}{ Means } & \multirow{2}{*}{$\begin{array}{l}\text { Mean Difference } \\
2.00\end{array}$} & \multirow{2}{*}{$\begin{array}{l}\text { P-Value (Sig.) } \\
.07\end{array}$} \\
\hline $\begin{array}{l}\text { Judo } \\
\text { (5.20) }\end{array}$ & $\begin{array}{l}\text { Taekwondo } \\
\text { (7.20) }\end{array}$ & & \\
\hline & $\begin{array}{l}\text { Boxing } \\
(8.60)\end{array}$ & 3.40 & $.00^{*}$ \\
\hline \multirow[t]{2}{*}{$\begin{array}{l}\text { Taekwondo } \\
(7.20)\end{array}$} & $\begin{array}{l}\text { Judo } \\
(5.20)\end{array}$ & 2.00 & .07 \\
\hline & $\begin{array}{l}\text { Boxing } \\
(8.60)\end{array}$ & 1.40 & .20 \\
\hline \multirow[t]{2}{*}{$\begin{array}{l}\text { Boxing } \\
(8.60)\end{array}$} & $\begin{array}{l}\text { Judo } \\
(5.20)\end{array}$ & 3.40 & $.00^{*}$ \\
\hline & $\begin{array}{l}\text { Taekwondo } \\
\text { (7.20) }\end{array}$ & 1.40 & .20 \\
\hline
\end{tabular}

*Confident at 0.05

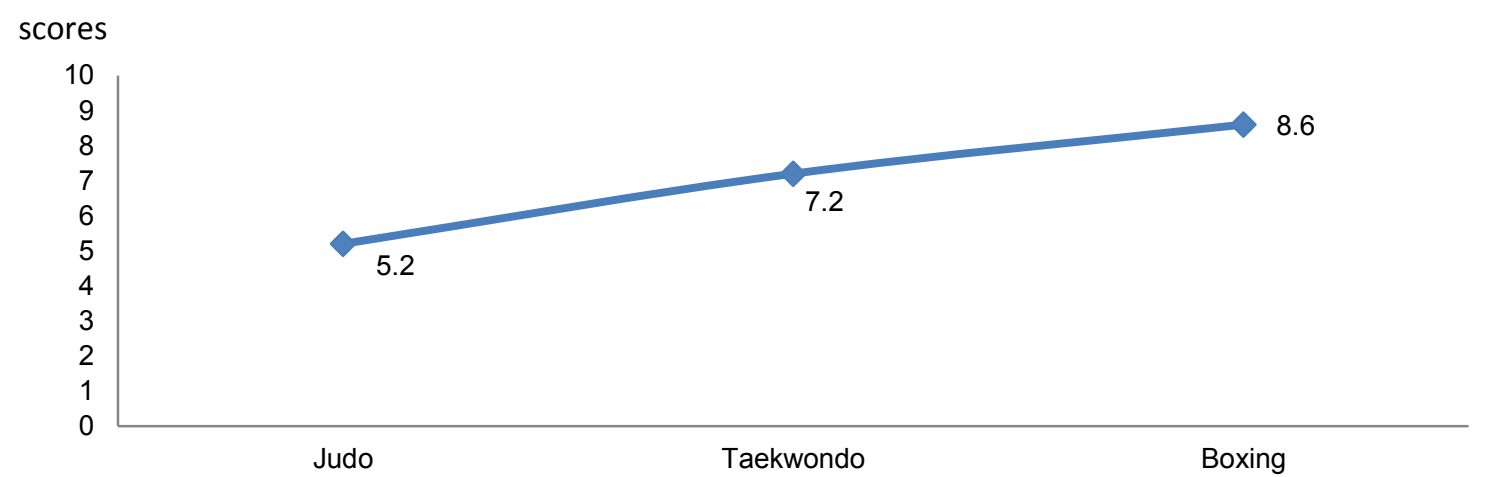

Figure 4. Graphical representation of mean scores with regard to judo, taekwondo and boxing players on the sub-parameter coach

Table 19. Descriptive analysis among judo, taekwondo and boxing players on the parameter superstitious (total)

\begin{tabular}{llllll}
\hline S. No. & Groups & N & Mean & Std. Deviation & Std. Error \\
\hline 1. & Judo & 10 & 99.30 & 13.67 & 4.32 \\
2. & Taekwondo & 10 & 108.60 & 19.02 & 6.01 \\
3. & Boxing & 10 & 102.60 & 18.91 & 5.97 \\
& Total & 30 & 103.50 & 17.22 & 3.14 \\
\hline
\end{tabular}

Table 19 depicts the results among Judo, Taekwondo and Boxing players on the parameter Superstitious (Total). The scores of judo players showed the Mean and SD values as 99.30 and 13.67 respectively. The scores of taekwondo players showed the Mean and SD values as 108.60 and 19.02 respectively. However, the scores of boxing players showed had Mean and SD values as 102.60 and 18.91 respectively.

Table 20. One way analysis of variance (Anova) results among judo, taekwondo and boxing players with regard to the parameter superstitious (total)

\begin{tabular}{llllll}
\hline Source of Variation & Sum of Squares & $\begin{array}{l}\text { Degree } \\
\text { of Freedom }\end{array}$ & Mean Square & F-Value & $\begin{array}{l}\text { P-Value } \\
\text { (Sig.) }\end{array}$ \\
\hline Between Groups & 444.60 & 2 & 222.30 & & \\
Within Groups & 8160.90 & 27 & 302.25 & .73 & .48 \\
Total & 8605.50 & 29 & & & \\
\hline
\end{tabular}

*Confident at 0.05

It can be seen from Table 20 that insignificant differences were found with regard to the parameter Superstitious (Total)among Judo, Taekwondo and Boxing players as the P-value (Sig.) .48 was found higher than 
the 0.05 level of significance ( $p>0.05$ ). Since F-value was found insignificant, therefore, there is no need to apply Post-hoc test.

\section{Discussion}

It has been observed from the Table 1 to 3 that significant differences have been found among Judo, Taekwondo and Boxing players on the sub-parameter Clothing and Appearance. While calculating the mean values of all the groups, it was observed that taekwondo players had demonstrated significantly better clothing and appearance as compared to their counterpart Judo and Boxing players. The outcome of results might be due to the fact that taekwondo players to dress well to feel better prepared for game and also get hair cut on the day of game. It is clearly illustrated from the Table 4 to 5 that insignificant differences have been found among Judo, Taekwondo and Boxing players with regard to the sub-parameter Fetish. It can be safely summarized that individual players were equally developed on the above said sub-parameter. The results might be attributed to the fact that all the individual players(Judo, Taekwondo and Boxing) on the sub-parameter has think that team mascot and wear a lucky charm help on the day of competition. Wilson [14] examined that highly identified fans reported wanting to perform more superstitious behavior than low identified fans.

It has been observed from the results (Table 6 to 8 ) that significant differences were found on the subparameter Preparation. While comparing the mean values of the entire groups, it has been noticed that taekwondo players demonstrated significantly better Preparation than their counterpart Judo and Boxing players. It can be presumed that taekwondo players have the ability to prepare for competition to face any situation as compared to their counterpart Judo and Boxing players. However, no significant differences were noticed (Table 9 to 10) on the sub-parameter; Game/competition among Judo, Taekwondo and Boxing players. It can be safely summarized that judo, taekwondo and boxing players were equally developed on the above said sub-parameter. George and Sreedhar [5] concluded that significant effect with students coming from urban area believing more in superstitious than those coming from rural area.

It is evident from (Table 11 to 13) results that significant differences were found among judo, taekwondo and boxing players with regard to the sub-parameter Team Ritual. While comparing the mean values of the entire groups, it has been noticed that Judo players demonstrated significantly better Team Ritual than their counterpart taekwondo and boxing players. It shows that judo players are more determined to cheering during the competition which helps to perform as highest level. The insignificant differences were obtained (Table 14 to 15) judo, taekwondo and boxing players on the sub-parameter Prayer. It has been found that entire players exhibit prayer for success before each and every game.

The obtained results (Table 16 to 18 ) showed significant differences on the sub-parameter Coach among Judo, Taekwondo and Boxing players. While calculating the mean values of entire groups, it has been observed that Boxing players demonstrate significantly better on the sub-parameter Coach. Therefore, it can be ascertained that Boxing players are more confident that coach bring a lucky charm to our game. It is evident from (Table 19 to 20) results that insignificant differences were found among Judo, Taekwondo and Boxing players on the parameter Superstitious (Total). It has been observed that entire Individual players demonstrate were equally better on the parameter Superstitious (Total). Bal et al. [1] revealed significant intra-group differences among individual, dual and team sports on the variable superstitious behavior.

\section{Conclusion}

It is concluded that results revealed significant differences among Judo, Taekwondo and Boxing players on the sub parameters: clothing and appearance, preparation, team ritual and coach. However, no significant differences have been observed on the sub parameters fetish, game/competition, prayer and parameter superstitious (Total).

\section{Conflict of interests}

The authors declare that there is no conflict of interests.

\section{References}

1. Bal BS, Singh D, Badwal KK, \& Dhaliwal GS. Superstitions behaviour and decision making in collegiate athletes: An illogical phenomenon. Advances in Physical Education, 2014;4(1):1-5.

2. Bleak JL, \& Frederick CM. Superstitious behavior in sport: levels of effectiveness and determinants of use in three collegiate sports. Journal of Sport Behavior, 1998;21:1-15.

3. Brooks M. Born believers: How your brain creates God. New Scientist Magazine, 2009;201:30-33.

4. Cicero H. Pietas: selected studies in roman religion. Leiden, Netherlands: Brill; 1980.

5. George S, \& Sreedhar KP. Globalisation and the prevalence of superstitious beliefs. Journal of the Indian Academy of Applied Psychology, 2006;32(3):241-247.

6. Heider F. The psychology of interpersonal relations. New York: Wiley; 1958.

7. Hollander ED. Principles and methods of social psychology. 2nd Edition; New York: Oxford University Press; 1971.

8. Johada G. Superstition and emotional maladjustment. Journal of Educational Research, 1969;28(8):592-617. 
9. Skinner BF. "Superstition" in the pigeon. Journal of Experimental Psychology, 1948;38:168-172.

10. Turcan R. The Cults of the Roman Empire. Nevill, Antonia (trans.).Oxford English Dictionary (Second ed.). Oxford University Press; 1996.

11. Van Raalte JL, Brewer BW, Neneroff CJ, \& Linder DE. Chance orientation and superstitious behaviour on the putting green. Journal of Sport Behavior, 1991;14:41-50.

12. Wann DL, Grieve FG, End C, Zapalac RK, Lanter JR, Pease DG, \& Wallace A. Examining the superstitious behaviors of sports fans: Types of superstitions, perceptions of impact, and relationship with team identification. Athletic Insight, 2010;5:21-44.

13. Weiner B. History of motivational research in education. Journal of Educational Psychology, 1990;82:616622.

14. Wilson S. The relationship between superstitious behaviours of sports. (Unpublished Master's Dissertation). Western Kentucky University; 2011.

15. Womack M. Why athletes need ritual: A study of magic among professional athletes. In S.J. Hoffman (Ed.), Sport and religion (pp. 191-202). Champaign, IL: Human Kinetics; 1992.

16. Rotter Julian B. Generalized expectancies for internal versus external control of reinforcement. Psychological Monographs: General and Applied, 1966;80(1):1-28. http://dx.doi.org/10.1037/h0092976

\section{Information about the authors:}

Gaurav Dureja; Assistant Professor; http://orcid.org/00000003-0508-6387; g_dureja83@yahoo.com; Department of Physical Education-TE\&L, Post Graduate Government College; Madhya Marg, Sector 11D, Chandigarh, 160011, India.

Gagandeep Singh; M.Phil. Scholar; http://orcid.org/00000002-7553-4301; g_dureja83@yahoo.com; Department of Physical Education-TE\&L, Post Graduate Government College; Madhya Marg, Sector 11D, Chandigarh, 160011, India.

Cite this article as: Gaurav Dureja, Gagandeep Singh. Superstitious behavior among judo, taekwondo and boxing players. Physical education of students, 2016;2:50-59. doi:10.15561/20755279.2016.0208

The electronic version of this article is the complete one and can be found online at: http://www.sportpedu.org.ua/html/arhive-e.html

This is an Open Access article distributed under the terms of the Creative Commons Attribution License, which permits unrestricted use, distribution, and reproduction in any medium, provided the original work is properly cited (http://creativecommons.org/licenses/by/4.0/deed.en).

Received: 03.03.2016

Accepted: 29.03.2016; Published: 25.04.2016 